\title{
RANCANGAN MEDIA PEMBELAJARAN HEWAN PURBAKALA MENGGUNAKAN AUGMENTED REALITY
}

\author{
Sampurna Dadi Riskiono ${ }^{1}$, Try Susanto ${ }^{2}$ dan Kristianto ${ }^{3}$
}

1,2,3 Universitas Teknokrat Indonesia

Jl. Z.A. Pagar Alam N0.9-11, Bandar Lampung 35132 INDONESIA

${ }^{1}$ sampurna.go@teknokrat.ac.id, ${ }^{2}$ try_susanto@teknokrat.ac.id, ${ }^{3}$ kristianto328@gmail.com

\begin{abstract}
Abstrak- Penelitian ini dilakukan bertujuan untuk membuat rancangan sebuah media pembelajaran yang inovatif dan menarik. Dengan kemudahan untuk memperkenalkan hewan yang hidup pada zaman prasejarah ke dalam bentuk yang lebih nyata pada murid sekolah. Rancangan aplikasi augmented reality pembelajaran hewan purbakala dibangun dengan menggunakan beberapa tools seperti Unity, Vuforia dan Blender. Nilai tambah dari aplikasi yang dibuat yaitu dengan diterpakannya metode marker based pada aplikasi media pembelajaran yang berjenis augmented reality, hal ini bertujuan agar semakin menarik dan meningkatkan minat belajar siswa. Hasil penelitian ini adalah Aplikasi Media Pembelajaran yang berjalan pada platform android. Untuk mendapatkan aplikasi yang berfungsi secara keseluruhan, maka aplikasi Augmented Reality Media Pembelajaran ini diuji menggunakan BlackBox dengan hasil lulus uji fungsional sistem.
\end{abstract}

Kata Kunci- Augmented Reality, Vuforia, Unity, Marker based, Rancangan Media Pembelajaran.

Abstract- This research was conducted to create innovative and interesting learning media. With pleasure to introduce animals that lived in prehistoric times into a more tangible form in school students. The design of augmented reality applications learning ancient animals built using several tools such as Unity, Vuforia and Blender. The added value of the application made is by applying marker method based on the application of augmented reality learning media, this encourages learning to be interesting and increases student learning interest. The results of this study are Learning Media Applications that run on the Android platform. To get an application that works with the whole, then this Augmented Reality Learning Media application uses BlackBox with the results of passing the system functional test.

Keywords - Augmented Reality, Vuforia, Unity, Marker based, Learning Media Design.

\section{PENDAHULUAN}

Dahulu, ketika zaman prasejarah, manusia belum mengenal tulisan. Zaman prasejarah ini di perkirakan dimulai sejak adanya kehidupan di permukaan bumi hingga manusia mengenal tulisan. Masa prasejarah tidak meninggalkan bukti-bukti tertulis pada bendabenda peninggalannya saat ini[1]. Dalam hal ini zaman prasejarah terbagi kedalam beberapa periode, yang salah satunya adalah zaman mesozoikum yang berlangsung selama 140 juta tahun yang lalu, dimana ditandai dengan munculnya reptil raksasa seperti dinosaurus dan atlantasurus, serta jenis ikan, burung dan hewan menyusui lainnya yang kita sebut hewan purbakala atau hewan prasejarah saat ini[2]. Saat ini, untuk mempelajari berbagai macam hewan purbakala anak-anak hanya dapat mempelajarinya lewat buku saja. Dimana buku tersebut hanya menampilkan gambar berupa fosil hewan purbakala yang pernah ditemukan namun tanpa mengetahui bagaimana bentuk dari hewan purbakala itu sendiri. Namun, dengan perkembangan saat ini munculah berbagai macam teknologi yang dapat memudahkan dalam proses pembelajaran. Salah satunya adalah teknologi augmented reality. Dengan adanya teknologi augmented reality, maka pengguna dapat melihat objek maya yang diproyeksikan terhadap dunia nyata dengan bentuk 3 dimensi yang menarik[3], [4].

Sejalan dengan teknologi animasi yang semakin berkembang dan kebutuhan akan tampilan 3 dimensi yang memiliki kualitas baik, maka untuk memenuhi kebutuhan tersebut digunakan teknologi augmented reality. Augmented Reality adalah sebuah istilah yang digunakan dalam lingkungan yang memadukan antara dunia nyata dan dunia virtual yang diprogram oleh komputer, sehingga batas antara keduanya menjadi sangat tipis[5].

Augmented reality memiliki prinsip kerjanya yang bersifat interaktif, realtime dan objek yang ditampilkan dalam bentuk 3 dimensi. Keunggulan dari teknologi augmented reality itu sendiri yaitu pengembngannya yang lebih mudah dan lebih murah, nilai tambah lainnya yaitu teknologi augmented reality dapat diimplementasikan secara luas dalam berbagai media. Dapat dijadikan sebagai sebuah aplikasi di dalam smartphone dan media cetak seperti koran, buku, dan majalah[6]. 
Pemamfaatan marker bergambar hewan yang dicetak di atas kertas bertujuan agar menarik untuk anak-anak. Ketika aplikasi diarahkan ke media marker, maka secara otomatis gambar hewan berbentuk 3 dimensi akan muncul dari dalam marker yang di sorot tersebut. Melalui media pembelajaran ini diharapkan anak-anak dapat lebih aktif dan bersamangat dalam mempelajari tentang hewan purbakala[7]. Maka pada penelitian ini, peneliti menerapkan teknologi augmented reality untuk dapat membuat sebuah media pembelajaran interaktif yang menggunakan objek 3 dimensi sebagai konten didalamnya. Marker yang digunakan untuk aplikasi ini adalah berupa gambar dari hewan itu sendiri, disini peneliti menggunakan media single marker yaitu penggunaan marker untuk masing-masing gambar bukan menggunakan multi marker yaitu satu marker dapat menampilkan banyak objek 3 dimensi[8].

Dari segi karakteristik, virtual, dan teknologi, media pembelajaran yang berbasis augmented reality ini dapat dikembangkan lebih lanjut baik dalam bentuk mobile maupun desktop.

\section{METODE PENELITIAN}

\section{A. Metode Pengumpulan Data}

Metode penelitian merupakan aktivitas yang dilakukan oleh peneliti sebelum melakukan perancangan system, hal ini dilakukan sebagai upaya untuk menganalisa permasalahan yang ada, dan juga memudahkan peneliti dalam mengatasi permasalahan yang timbul [9]. Untuk alurnya seperti di perlihatkan pada Gbr. 1 .

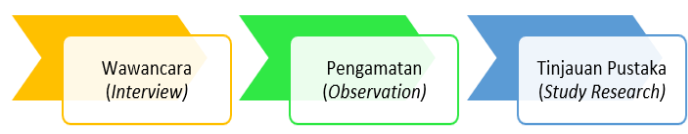

Gbr. 1 Metode Penelitian

\section{Wawancara (Interview)}

Pengumpulan data dengan metode wawancara yaitu metode pengumpulan data yang dilakukan dengan tanya jawab secara langsung kepada guru yang bersangkutan sesuai dengan topik yang akan dibahas.

\section{Pengamatan (Observation)}

Peneliti melakukan pengamatan secara langsung ke lokasi penelitian, mengamati secara langsung lokasi yang diteliti. Hal ini dilakukan untuk mendapat data yang akurat serta gambaran yang jelas untuk dasar penelitian yang akan dilakukan

3. Tinjauan Pustaka (Study Research)

Tinjauan Pustaka merupakan pencarian sumber sumber atau opini pakar tentang suatu hal yang berkaitan dengan tujuan penelitian. Proses pengumpulan data yang dilakukan dengan mempelajari berbagai bentuk bahan tertulis berupa buku, jurnal, artikel dan dokumendokumen yang ada kaitan nya secara langsung [10].

\section{B. Perancangan dan Pemodelan Sistem}

Alur kerja pada aplikasi augmented reality ini akan di gambarkan dalam bentuk flowchart. Agar pengguna dapat lebih mudah dalam memahami proses pendeteksian marker pada aplikasi augmented reality pengenalan hewan purbakala dapat dilihat pada Gbr. 2 dibawah ini.

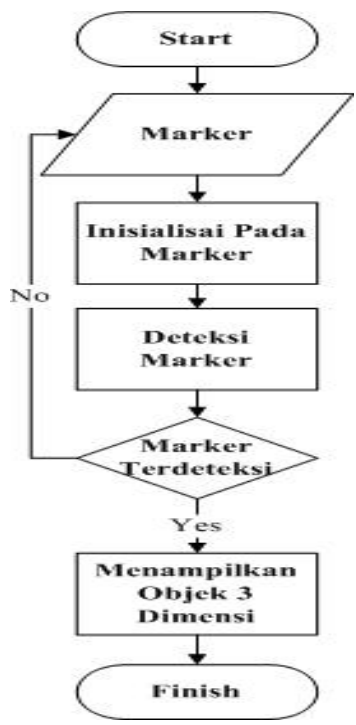

Gbr.2 Flowchart Aplikasi Augmented reality

Pada proses untuk pendeteksian marker, di awali dengan pengguna yang mengarahkan marker pada kamera di smartphone. Kemudian setelah posisinya sesuai, maka kamera akan mendeteksi marker tersebut. Pada proses pendeteksian marker ini bergantung kepada beberapa hal seperti, intensitas cahaya, jarak antara marker dengan kamera, ataupun pendeteksian marker yang terhalang oleh objek lain. Jika marker tidak terdeteksi pada kamera, maka pengguna harus mengatur ulang posisi marker dan mengarahkannya kembali dengan posisi menghadap pada kamera. Jika marker sudah terdeteksi, maka aplikasi akan menampilkan objek 3 dimensi yang berada dalam marker tersebut.

\section{Use Case Diagram}

Use case diagram mendeskripsikan sebuah interaksi antara satu atau lebih aktor dengan sistem yang akan dibuat. Use case digunakan untuk mengetahui fungsi apa saja yang ada didalam sebuah sistem Pada Use case diagram ini terdapat aktor. Penjelasan mengenai aktor dapat dilihat pada Tabel 1 dibawah ini. 
TABEL I

AKTOR USE CASE

\begin{tabular}{|l|l|l|}
\cline { 2 - 3 } & Nama Aktor & \multicolumn{1}{c|}{ Definisi } \\
\cline { 2 - 3 } Page | 201 & User & $\begin{array}{l}\text { Orang yang berinteraksi dengan sistem, } \\
\text { yaitu pengguna yang dapat menggunakan } \\
\text { semua fungsi yang disediakan oleh } \\
\text { sistem }\end{array}$ \\
\hline
\end{tabular}

Berikut ini adalah table deskripsi use case yang dapat dilihat pada Tabel 2 dibawah ini.

$$
\text { TABEL II }
$$

DESKRIPSI USE CASE

\begin{tabular}{|c|c|c|c|}
\hline No & $\begin{array}{c}\text { Kode Use } \\
\text { Case }\end{array}$ & $\begin{array}{c}\text { Nama Use } \\
\text { Case }\end{array}$ & Deskripsi \\
\hline 1. & UC-P01 & Baca Marker & $\begin{array}{l}\text { Proses awal } \\
\text { memulai aplikasi }\end{array}$ \\
\hline 2. & UC-P02 & Pilih Zaman & $\begin{array}{l}\text { Sebelum masuk } \\
\text { pada deteksi marker } \\
\text { harus memilih } \\
\text { zaman Yang } \\
\text { tersedia }\end{array}$ \\
\hline 3. & UC-P03 & $\begin{array}{l}\text { Mendeteksi } \\
\text { Kamera }\end{array}$ & $\begin{array}{l}\text { Aplikasi akan } \\
\text { mendeteksi } \\
\text { ketersediaan kamera }\end{array}$ \\
\hline 4. & UC-P04 & $\begin{array}{l}\text { Mendeteksi } \\
\text { Marker }\end{array}$ & $\begin{array}{l}\text { Aplikasi mendeteksi } \\
\text { keberadaan marker }\end{array}$ \\
\hline 5. & UC-P05 & $\begin{array}{l}\text { Menampilkan } \\
\text { Objek } 3 \\
\text { dimensi }\end{array}$ & $\begin{array}{l}\text { Aplikasi akan } \\
\text { menampilkan objek } \\
3 \text { dimensi }\end{array}$ \\
\hline 6. & UC-P06 & $\begin{array}{l}\text { Animasi } \\
\text { Objek }\end{array}$ & $\begin{array}{l}\text { Aplikasi akan } \\
\text { menggerakkan } \\
\text { objek yang } \\
\text { ditampilkan }\end{array}$ \\
\hline 7. & UC-P07 & $\begin{array}{l}\text { Suara } \\
\text { Deskripsi }\end{array}$ & $\begin{array}{l}\text { Mengeluarkan suara } \\
\text { deskripsi masing- } \\
\text { masing hewan }\end{array}$ \\
\hline 8. & UC-P08 & Info Profil & $\begin{array}{l}\text { Menampilkan profil } \\
\text { pembuat aplikasi }\end{array}$ \\
\hline 9. & UC-P09 & Info Panduan & $\begin{array}{l}\text { Menampilkan cara } \\
\text { menggunakan } \\
\text { aplikasi }\end{array}$ \\
\hline 10. & UC-P10 & $\begin{array}{l}\text { Info } \\
\text { Ensiklopedi }\end{array}$ & $\begin{array}{l}\text { Menampilkan info } \\
\text { manusia, alat, dan } \\
\text { hewan purba }\end{array}$ \\
\hline
\end{tabular}

\section{HASIL DAN PEMBAHASAN}

\section{A. Pembuatan Model 3 Dimensi}

Pada proses pembuatan objek dari model tiga dimensi menggunakan software blender. Dimana proses dapat dilihat pada Gbr. 3 dibawah ini.

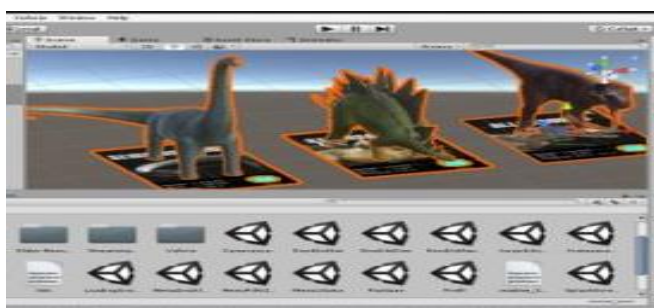

Gbr.3 Pembuatan Model 3 Dimensi

\section{B. Proses Membuat Menu Slider Ensiklopedi}

Proses pembuatan ensiklopedi dimulai dengan memasukkan asset berupa materi-materi yang dibutuhkan ke dalam asset kemudian dimasukkan kedalam kanvas dan memanfaatkan fitur slider. Penggunaan slider bertujuan agar pengguna lebih mudah untuk menggeser atau menggerakkan menu yang ada sehingga penggunaan slider ini akan menjadikan ensiklopedi lebih user friendly. Dapat dilihat pada Gbr. 4 dibawah ini.

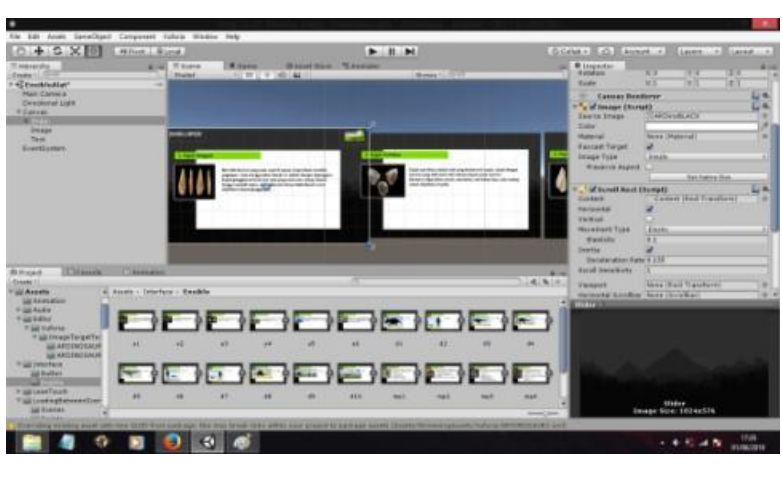

Gbr.4 Membuat Menu Slider Ensiklopedi

\section{Tampilan Panduan}

Pada tampilan ini, tampilan menu yang berisikan panduan atau cara kerja dari aplikasi media pembelajaran hewan purbakala menggunakan augmented reality, tampilan ini disertai gambar dan terdapat sebuah tombol "Back/Kembali" yang berfungsi sebagai alur untuk kembali ke menu utama. Seperti yang di perlihatkan pada Gbr. 5 dibawah ini.

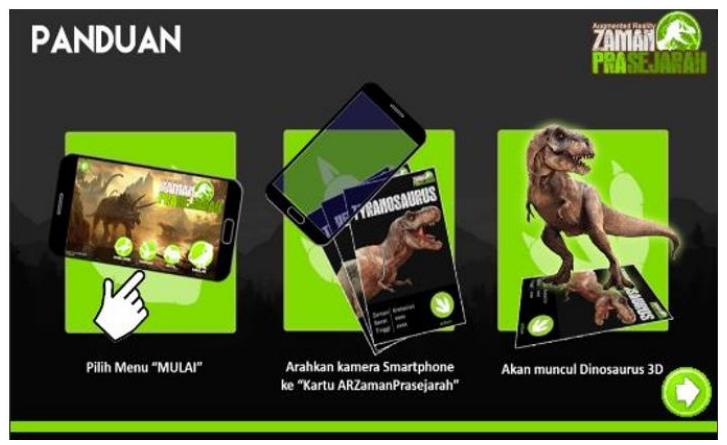

Gbr.5 Menu Panduan

\section{Tampilan Ensiklopedi}

Tampilan berikut ini merupakan Ensiklopedi yang berisikan mengenai materi-materi pembelajaran di antaranya adalah manusia purba, alat prasejarah, skala ukuran dinosaurus, dan deskripsi dinosaurus, pada menu ini pengguna dapat menggeser layar untuk melihat informasi yang ada. Dapat dilihat pada Gbr. 6 dibawah ini. 


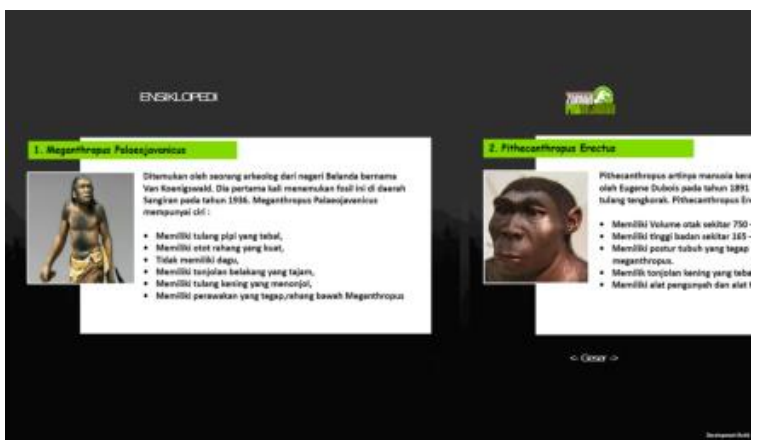

Gbr.6 Tampilan Ensiklopedi

\section{E. Tampilan Objek 3 Dimensi}

Berikut adalah hasil tampilan tiga dimensi yang menampilkan salah satu hewan purbakala yang disertai audio/suara serta deskripsi. Untuk visualisasi nya dapat dilihat pada Gbr. 7 dibawah ini.

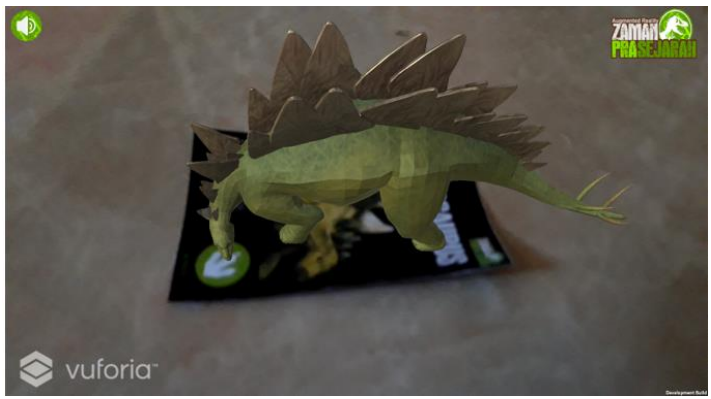

Gbr.7 Objek 3 Dimensi

\section{F. Pengujian Program}

Pengujian program merupakan aspek penting dalam pengmbangan sebuah perangkat lunak. Pengujian sistem diperlukan untuk mengetahui kesalahan-kesalahan program yang ada pada sistem serta untuk memastikan sistem yang dikembangkan telah sesuai dengan apa yang direncanakan sebelumnya.

\section{G. Pengujian Blackbox}

Pengujian blackbox atau uji fungsional adalah pengujian yang mengabaikan mekanisme internal sistem atau komponen. Pengujian ini hanya berfokus pada keluaran yang dihasilkan dalam menanggapi masukan yang dipilih dan kondisi eksekusi. Sehingga dapat disimpukan bahwa blackbox testing merupakan pengujian yang berorientasi pada fungsionalitas yaitu perilaku dari perangkat lunak atas masukan yang diberikan pengguna sehingga mendapatkan/ menghasilkan output yang diinginkan tanpa melihat proses internal atau kode program yang dieksekusi oleh perangkat lunak [11]. Rancangan pengujian yang dilakukan dalam aplikasi Augmented Reality Pembelajaran Hewan Purbakala ini menggunakan metode black box. Pengujian ini menitik beratkan pada fungsi sebuah sistem. Tabel rencana pengujian dapat dilihat pada Tabel 3 dibawah ini.

TABEL III

KOMPONEN RENCANA PENGUJIAN APLIKASI

\begin{tabular}{|c|c|}
\hline Kebutuhan Uji & Elemen Uji \\
\hline Menu Utama & $\begin{array}{l}\text { Tampilan Interface Menu Utama, } \\
\text { Fungsi Tombol Mulai, Profil, } \\
\text { Panduan, dan Ensiklopedi. }\end{array}$ \\
\hline Menu Profil & $\begin{array}{l}\text { Tampilan Informasi Pembuat } \\
\text { Aplikasi Augmented reality. }\end{array}$ \\
\hline Menu Panduan & $\begin{array}{l}\text { Tampilan Informasi Panduan } \\
\text { Penggunaan Aplikasi. }\end{array}$ \\
\hline Menu Ensiklopedi & $\begin{array}{l}\text { Tampilan Informasi Ensiklopedi } \\
\text { Manusia purba, Alat Prasejarah, } \\
\text { Skala Ukuran, dan Deskripsi Hewan. }\end{array}$ \\
\hline $\begin{array}{l}\text { Menu Tracking } \\
\text { Kamera }\end{array}$ & $\begin{array}{l}\text { Tampilan Objek } 3 \text { Dimensi, dan } \\
\text { Audio Deskripsi. }\end{array}$ \\
\hline Objek 3 Dimensi & $\begin{array}{l}\text { Tampilan Objek } 3 \text { Dimensi } \\
\text { (Tyrannosaurus Rex, Velociraptor, } \\
\text { Eoraptor, Spinosaurus, Allosaurus, } \\
\text { Seismosaurus, Riojasaurus, } \\
\text { Triceratops, Pterodatcyl, } \\
\text { Stegosaurus). }\end{array}$ \\
\hline Audio Deskripsi & $\begin{array}{l}\text { Terdengar Audio Deskripsi } \\
\text { (Tyrannosaurus Rex, Velociraptor, } \\
\text { Eoraptor, Spinosaurus, Allosaurus, } \\
\text { Seismosaurus, Riojasaurus, } \\
\text { Triceratops, Pterodatcyl, } \\
\text { Stegosaurus). }\end{array}$ \\
\hline Keluar & Aplikasi akan keluar \\
\hline
\end{tabular}

\section{H. Hasil Pengujian Blackbox}

Dari pengujian menggunakan metode black box diatas, seluruh tampilan dan konten telah berfungsi dengan semestinya. Dan dapat disimpulkan bahwa perangkat lunak yang dibangun bebas dari kesalahan fungsional.

\section{KESIMPULAN}

Hasil penelitian yang berjudul "Rancangan Media Pembelajaran Hewan Purbakala Menggunakan Augmented Reality" di dapat kesimpulan sebagai berikut:

1. Perancangan aplikasi augmented reality dalam mendukung media pembelajaran purbakala merupakan langkah yang baik, guna memberikan media pembelajaran yang lebih inovatif dan interaktif. 
2. Perancangan aplikasi media pembelajaran hewan purbakala menggunakan Augmented reality berhasil diimplementasikan dengan menggunakan beberapa alat pendukung seperti Unity, Blender dan Vuforia.

Page| 203 3. Dari hasil pengujian Black Box (Kotak Hitam) yang telah di lakukan, aplikasi ini telah bebas dari kesalahan fungsional, sehingga sangat baik untuk dikembangkan dimasa yang akan datang.

\section{UCAPAN TERIMA KASIH}

Ucapan Terima kasih kepada Direktorat Riset dan Pengabdian kepada Masyarakat (DRPM) Kemenristek /BRIN yang telah mendanai kegiatan penelitian ini yakni pada skema Penelitian Dosen Pemula (PDP) sesuai dengan SK Penetapan Pemenang Hibah PDP nomor: SP2H/LT/MONO/LL2/2020 April 2020. Terima kasih juga peneliti sampaikan kepada LPPM Universitas Teknokrat Indonesia yang telah memfasilitasi kegiatan penelitian ini.

\section{REFERENSI}

[1] Ari Listiyani, D.Sejarah untuk kelas X. Jakarta: Pusat Perbukuan Departemen Pendidikan Nasional, 2009.

[2] Hendrayana. Sejarah Kelas X. Jakarta: Departemen Pendidikan Nasional, 2009

[3] R. I. Borman, "Implementasi Augmented Reality pada Aplikasi Android Pegenalan Gedung Pemerintahan Kota Bandar Lampung," J. Teknoinfo, vol. 11, no. 1, p. 1, 2017.

[4] Thomas, B. Emerging technologies of augmented reality Interfaces and design. Hershey: Idea Group Publishing.2007

[5] R. T. Azuma, "A survey of augmented reality," Presence Teleoperators Virtual Environ., vol. 6, no. 2-3, pp. 355-385, 1997.

[6] Kaufmann, H. (2002). Collaborative Augmented Reality in Education. Education and Information Technologies, pp. 263276

[7] I. D. Gede, W. Dhiyatmika, I. K. Gede, D. Putra, N. Made, and I. Marini, "Aplikasi Augmented Reality Magic Book Pengenalan Binatang untuk Siswa TK," Lontar Komput., vol. 6, no. 2, pp. 589-596, 2015.

[8] Roedavan, R. Unity Tutorial Game engine. Bandung: Informatika, 2016

[9] Aini, Q., Rahardja, U., \& Naufal, R. S. Penerapan Single Sign On dengan Google pada Website berbasis YII Framework. Sisfotenika, 8(1), 57-68, 2018.

[10] Djiwandono, P. I. Meneliti itu Tidak Sulit: Metodologi Penelitian Sosial dan Pendidikan Bahasa. Deepublish, 2015.

[11] D. Febiharsa, I. M. Sudana, and N. Hudallah, "Uji Fungsionalitas (BlackBox Testing) Sistem Informasi Lembaga Sertifikasi Profesi (SILSP) Batik Dengan AppPerfect Web Test Dan Uji Pengguna," JOINED J., vol. 1, no. 2 , pp. $117-126,2018$. 